\title{
PSMB4 overexpression enhances the cell growth and viability of breast cancer cells leading to a poor prognosis
}

\author{
HUA WANG ${ }^{1}$, ZHIXIAN HE ${ }^{1}$, LIUWAN XIA ${ }^{2 *}$, WEI ZHANG ${ }^{1 *}$, LI XU $^{3}$, \\ XIAOSONG YUE ${ }^{2}$, XIAOYAN RU ${ }^{2}$ and YANBO XU ${ }^{2}$ \\ ${ }^{1}$ Department of General Surgery, Affiliated Hospital of Nantong University; \\ ${ }^{2}$ Clinical Medicine, Medical College, Nantong University, Nantong, Jiangsu 226001; \\ ${ }^{3}$ Department of Neurosurgery, Suzhou Municipal Hospital, Suzhou, Jiangsu, 215000, P.R. China
}

Received October 11, 2017; Accepted May 25, 2018

DOI: $10.3892 /$ or.2018.6588

\begin{abstract}
PSMB4, proteasome subunit $\beta 4$, is a member of the ubiquitin-proteasome family, and is elevated in a variety of malignancies. However, the expression level and related mechanism of PSMB4 in breast cancer remains unclear. Therefore, the present study investigated the expression level of PSMB4 in eight pairs of breast cancer and adjacent normal tissues. In addition, the relationship between the expression of PSMB4 and the clinical data of 92 breast cancer patients was discussed. First, it was found that PSMB4 expression was obviously upregulated in breast cancer tumor tissues and cell lines (MDA-MB-231 and MCF-7), and its level was significantly associated with tumor grade $(\mathrm{P}=0.005)$, tumor size $(\mathrm{P}=0.047)$, Ki-67 expression $(\mathrm{P}=0.040)$ and the poor prognosis of breast cancer. The present results demonstrated that PSMB4 could promote the proliferation of breast cancer cells, and was positively correlated with the expression of PCNA using an in vitro starvation-refeeding experiment. In addition, PSMB4-siRNA transfection assay suggested that PSMB4 knockdown can decrease NF- $\mathrm{KB}$ activity and cell viability, and result in cell cycle arrest at the G1/S phase. These findings revealed that PSMB4 might facilitate breast cancer progression by promoting cell proliferation and viability. In summary, PSMB4 may be recognized as an efficacious prognostic marker and potential therapeutic target for breast cancer.
\end{abstract}

Correspondence to: Dr Hua Wang or Dr Zhixian He, Department of General Surgery, Affiliated Hospital of Nantong University, Nantong, Jiangsu 226001, P.R. China

E-mail: 13706292250@163.com

E-mail: hezhixian@ntu.edu.cn

${ }^{*}$ Contributed equally

Key words: proteasome, $\beta 4$ subunit of the 20 S proteasome, PSMB4, breast cancer, cell proliferation, viability

\section{Introduction}

Breast cancer is the second most commonly diagnosed invasive cancer in women with 1.15 million cases diagnosed annually worldwide, and is the main cause of cancer-related mortality worldwide (1). In Western countries, studies have shown that one in eight women is likely to develop breast cancer (2). However, it remains difficult to elucidate the mechanisms of breast carcinogenesis. The diverse biochemistry and clinical background of breast cancer have led researchers to discover more efficacious markers and evaluation strategies for diagnosis and therapy.

A proteasome is an ATP-dependent multi-catalytic proteinase complex (3), which is crucial to the degradation of intracellular targeted proteins and the maintenance of significant biological functions $(4,5)$. Emerging evidence indicates that the proteasome plays a novel role in regulating anti-apoptotic and proliferative signaling pathways in a variety of malignancies, including breast cancer (6-9). Indeed, proteasome inhibition provides a unique approach to cancer therapy by depressing the function of proteasomes. Thus, proteasome inhibitors, such as carfilzomib and bortezomib, have been proven to be effective against cancers in human trials by target multifarious subunits $(10,11)$. PSMB4, a $\beta 4$ subunit of the $20 \mathrm{~S}$ proteasome, is a member of the ubiquitin-proteasome family, and is involved in the cytoplasmic protein catabolic process (12). More and more studies have revealed the correlation between PSMB4 expression and tumor tissues (13-18). The association of PSMB4 overexpression with increased $\mathrm{NF}-\kappa \mathrm{B}$ activity led to an increase in the proliferation ability of multiple myeloma and epithelial ovarian cancer $(13,14)$. In addition, PSMB4 expression is related to increased viability and the malignant progression of gliomas (15). Therefore, PSMB4 may be recognized as an efficacious marker and potential therapeutic target for breast cancer. However, its expression and extensional regulatory mechanism in breast cancer remains virtually unclear.

In the present study, the expression of PSMB4 was detected in breast cancer cell lines and tissues by immunohistochemistry and western blot analysis. In addition, the association of PSMB4 with the clinicopathological characteristics obtained from breast cancer patients was discovered. Next, the functional 
significance of PSMB4 was explored in cultured breast cancer cells by siRNA gene silencing. These results show that PSMB4 is a novel regulator of breast cancer cell proliferation and a potential therapeutic target in breast cancer.

\section{Materials and methods}

Patients and tissue samples. Breast specimens were obtained from 92 patients who underwent excision of breast cancer tumors at the Department of General Surgery, Affiliated Hospital of Nantong University from 2006 to 2012. The present study was approved by the Ethics Committee of the Affiliated Cancer Hospital of Nantong University (Nantong, China) Fresh breast cancer tissues were collected and immediately stored in liquid nitrogen. Lobular carcinoma or other histological types were confirmed at the Department of Pathology, the Affiliated Hospital of Nantong University. The detailed clinical information of patients was obtained by telephone or interview with the patients. All patients provided a written informed consent. For histological analysis, the specimens were fixed in formalin and embedded in paraffin. The protein of 8 tumorous and adjacent non-tumorous tissue samples was analyzed by western blot analysis. After receiving the authorization of the patients, the detailed information of the patients, including age, tumor grade, estrogen receptor (ER) status, progesterone-receptor (PR) status, Her2 status, tumor size, lymph node status, histologic grade and Ki-67, were obtained. The data are presented in Table I.

Immunohistochemistry (IHC). The specimens (4- $\mu \mathrm{m}$ thick) were mounted on glass slides embedded in paraffin and coated with $10 \%$ formalin. Next, the tissue sections were deparaffinized with xylene and rehydrated with graded alcohol washes. Then, the antigen was retrieved using citrate buffer $(\mathrm{pH}$ 6.0) by heating to $120^{\circ} \mathrm{C}$ for $3 \mathrm{~min}$. After douching in phosphatebuffered saline (PBS) (pH 7.2), the sections were incubated with rabbit anti-PSMB4 antibody (1:1,000; cat. no. 11029-1-AP; ProteinTech Group, Inc., Chicago, IL, USA) and rabbit antiKi-67 antibody (1:1,000; Santa Cruz Biotechnology, Inc., Dallas, TX, USA) at $4^{\circ} \mathrm{C}$ overnight. The slides were washed three times with PBS, and were incubated using a 2-step Plus Poly-HRP anti-mouse/rabbit IgG detection system (ZSGB-Bio; OriGene Technologies, Inc., Beijing, China) at room temperature for $30 \mathrm{~min}$. Next, each section was washed with PBS and the sections were incubated with 3,3'-diaminobenzidine (DAB). After washing in water, the sections were counterstained with hematoxylin to visualize normal nuclei, dehydrated in a series of graded alcohol, and cover-slipped on microslide glass. The observers who evaluated the sections were blinded to the characteristics of the patients.

Cell culture and siRNA transfection. MDA-MB-231 and MCF-7 cells were the human breast cancer cell lines used (Department of Oncology, the Affiliated Cancer Hospital of Fudan University). MCF-7 was obtained and cultured in RPMI-1640 medium, while MDA-MB-231 cells were cultured in L15 medium (both from Gibco-BRL, Grand Island, NY,USA) at $37^{\circ} \mathrm{C}$ in an incubator with $5 \% \mathrm{CO}_{2}$. Both types of mediums were supplemented with $10 \%$ heat inactivated fetal bovine serum (FBS). The PSMB4-specific siRNAs were synthesized by Shanghai GeneChem Co., Ltd., (Shanghai, China). The siRNA target sequence of PSMB4 included the following: PSMB4-siRNA\#1, 5'-GCUAUAGUCCUAGAGCUAU-3' and PSMB4-siRNA\#2, 5'-GCUAUUCAUU CAUGGCUGA-3'. According to the manufacturer's instructions, when $80 \%$ confluency was reached, MDA-MB-231 and MCF-7 cells were transfected with the PSMB4-siRNA or control siRNA, and were harvested for follow-up experiments after transfection for $48 \mathrm{~h}$. Cell transfection was performed with Lipofectamine 2000 (Invitrogen; Thermo Fisher Scientific, Inc., Waltham, MA, USA), according to the manufacturer's instructions.

Protein extraction and western blot analysis. Cells were washed with ice-cold PBS for three times and resuspended in lysis buffer $(50 \mathrm{mM}$ of Tris- $\mathrm{HCl}, 120 \mathrm{mM}$ of $\mathrm{NaCl}, 0.5 \%$ of Nonidet P-40, $100 \mathrm{mM}$ of NaF, $200 \mu \mathrm{M}$ of $\mathrm{Na}_{3} \mathrm{VO}_{4}$, and a protease inhibitor mixture). Next, the sample was centrifuged at $12,000 \mathrm{rpm}$ for $30 \mathrm{~min}$ at $4^{\circ} \mathrm{C}$ to obtain the supernatant. Then, the protein concentration was detected using the BioRad protein assay (Bio-Rad Laboratories, Hercules, CA, USA). Next, the protein samples were denatured in water at $100^{\circ} \mathrm{C}$ for $3 \mathrm{~min}$. Then, the proteins were separated using sodium dodecyl sulfate-polyacrylamide gel electrophoresis (SDS-PAGE) and transferred onto polyvinylidene difluoride filter (PVDF) membranes (EMD Millipore Corp., Billerica, MA, USA). After blocking the membranes with 5\% dried skim milk in Tris-buffered saline Tween-20 (TBST) for $2 \mathrm{~h}$, these were incubated with antibodies overnight at $4^{\circ} \mathrm{C}$ and washed with TBST for three times for $5 \mathrm{~min}$ each time. Then, the membranes were incubated with horseradish peroxidase-linked $\operatorname{IgG}$ for $2 \mathrm{~h}$. Finally, the bands were detected using the ECL detection system (Pierce, Rockford, IL, USA). The densities of bands were compared using ImageJ (NIH, Bethesda, MD, USA).

Flow cytometric analyses of cell cycle distribution and cell apoptosis. After serum deprivation for $72 \mathrm{~h}$, the cells were incubated with complete medium for 4, 8, 12 and $24 \mathrm{~h}$. Then, the cells were strictly collected at every time-point. The MDA-MB-231 and MCF-7 cells were transfected with PSMB4-siRNA, according to manufacturer's instructions. The MDA-MB-231 and MCF-7 cells were harvested and fixed with $70 \%$ ice-cold ethanol for at least $24 \mathrm{~h}$. Then, DNA-staining solution $[25 \mu \mathrm{g} / \mathrm{ml}$ of propidium iodide (PI), $100 \mu \mathrm{g} / \mathrm{ml}$ of RNase A, and $0.5 \%$ Nonidet P-40 in PBS] was added to stain the cells at room temperature for $20 \mathrm{~min}$. Next, the DNA content was analyzed from $1 \times 10^{4}$ cells using the Muse ${ }^{\mathrm{TM}}$ cell analyzer (EMD Millipore Corp.). Each experiment was performed in triplicate.

In order to analyze apoptosis, the cells were double-stained using an Annexin V-FITC/PI apoptosis detection kit (BBI), and analyzed using the FACSCalibur flow cytometer.

Plate colony formation assay. The MDA-MB-231 and MCF-7 cells transfected with PSMB4-siRNA\#1 were seeded in $2 \mathrm{ml}$ of L15 or RPMI-1640 supplemented with $10 \%$ FBS in 6 -well plates at $5 \times 10^{3}$ per well. After 2 weeks, each well was washed with PBS. Next, the colonies were fixed with $4 \%$ paraformaldehyde for $20 \mathrm{~min}$. Finally, the colonies were stained with $0.4 \%$ crystal violet for $30 \mathrm{~min}$ at room temperature. The 
Table I. Correlation between PSMB4 expression and the clinicopathological factors of the breast cancer cases.

\begin{tabular}{|c|c|c|c|c|c|}
\hline \multirow{2}{*}{$\begin{array}{l}\text { Patient } \\
\text { characteristics }\end{array}$} & \multirow[b]{2}{*}{ Total } & \multicolumn{2}{|c|}{$\begin{array}{c}\text { PSMB4 } \\
\text { expression }\end{array}$} & \multirow[b]{2}{*}{ P-value } & \multirow[b]{2}{*}{$\chi^{2}$} \\
\hline & & Low & High & & \\
\hline \multicolumn{6}{|l|}{ Age (years) } \\
\hline$\leq 50$ & 48 & 19 & 29 & 0.297 & 0.586 \\
\hline$>50$ & 44 & 15 & 29 & & \\
\hline \multicolumn{6}{|l|}{ Tumor grade } \\
\hline $\mathrm{I}$ & 8 & 7 & 1 & $0.005^{\mathrm{b}}$ & 10.578 \\
\hline II & 43 & 16 & 27 & & \\
\hline III & 41 & 11 & 30 & & \\
\hline \multicolumn{6}{|l|}{ ER status } \\
\hline Negative & 40 & 14 & 26 & 0.733 & 0.116 \\
\hline Positive & 52 & 20 & 32 & & \\
\hline \multicolumn{6}{|l|}{ PR status } \\
\hline Negative & 69 & 25 & 44 & 0.803 & 0.062 \\
\hline Positive & 23 & 9 & 14 & & \\
\hline \multicolumn{6}{|l|}{ Her2 status } \\
\hline Negative & 68 & 27 & 41 & 0.358 & 0.846 \\
\hline Positive & 24 & 7 & 17 & & \\
\hline \multicolumn{6}{|c|}{ Tumor size $(\mathrm{cm})$} \\
\hline$\leq 2.5$ & 34 & 17 & 17 & $0.047^{\mathrm{b}}$ & 3.938 \\
\hline$>2.5$ & 58 & 17 & 41 & & \\
\hline \multicolumn{6}{|c|}{ Lymph node status } \\
\hline Negative & 34 & 15 & 19 & 0.276 & 1.187 \\
\hline Positive & 58 & 19 & 39 & & \\
\hline \multicolumn{6}{|l|}{ Histology } \\
\hline Ductal & 76 & 28 & 48 & 0.960 & 0.002 \\
\hline Others & 16 & 6 & 10 & & \\
\hline \multicolumn{6}{|l|}{ Ki-67 } \\
\hline Low & 44 & 21 & 23 & $0.040^{\mathrm{b}}$ & 4.199 \\
\hline High & 48 & 13 & 35 & & \\
\hline
\end{tabular}

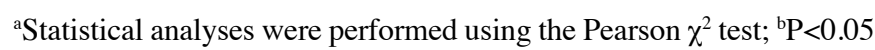
is considered statistically significant. ER, estrogen receptor; PR, progesterone-receptor.

efficiency of the assay was the following: Clone forming efficiency $=$ number of colonies/number of inoculated cells $\times 100 \%$.

Immunohistochemical evaluation. Two independent investigators randomly examined every section in a blinded manner using a Leica fluorescence microscope (Leica Microsystems $\mathrm{GmbH}$, Wetzlar, Germany). Five fields were chosen from each slide, counting $>1,000$ cells on each view at high magnification. In order to objectively make an assessment of the immunoreaction of PSMB4, the staining intensity was divided into scores 0-3 (0, negative staining; 1 , weak staining; 2, moderate staining; 3 , strong staining). Based on the proportion of PSMB4 expression and positive tumor cells, patients were categorized into four groups: Negative $(<10 \%, 1)$, low
$(10-35 \%, 2)$, moderate $(36-50 \%, 3)$, and high $(>50 \%, 4)$. The immunostaining score was calculated as the staining intensity score $\mathrm{x}$ the positive cell percentage score. As a result, if the total value was $>6$, the sample was assigned a high grade, and if the value was $<6$, the sample was assigned a low grade.

Antibodies. The antibodies applied for the immunohistochemistry and western blot analysis in the present study were as follows: Rabbit anti-PSMB4 monoclonal antibody $(1: 1,000$; cat. no. 11029-1-AP; ProteinTech Group, Inc., Chicago, IL, USA), mouse anti-human Ki-67 monoclonal antibody (1:1,000; cat. no. sc-23900), mouse anti-human cyclin D1 polyclonal antibody (1:1,000; cat. no. sc-8396) (both from Santa Cruz Biotechnology, Inc., Santa Cruz, CA, USA), rabbit anti-P-P65 monoclonal antibody (1:800; cat. no. 3033), rabbit anti-Ік $\beta \alpha$ monoclonal antibody (1:1,000; cat. no. 76041) (both from Cell Signaling Technology, Danvers, MA, USA), rabbit anti-Bax monoclonal antibody (1:1,000; cat. no. sc-493), mouse antihuman Bcl-2 monoclonal antibody (1:1,000; cat. no. sc-509), mouse anti-human PCNA monoclonal antibody $(1: 1,000$; cat. no. sc-25280) (all from Santa Cruz Biotechnology, Inc.), mouse anti-human PARP monoclonal antibody (1:800; cat. no. sc-136208; Cell Signaling Technology) and rabbit anti-human GAPDH polyclonal antibody (1:5,000; cat. no. 10494-1-AP; ProteinTech Group, Inc.).

Statistical analysis. The expression of PSMB4 and its correlation with clinicopathological features of breast cancer were investigated using the Chi-square $\left(\chi^{2}\right)$ test. In order to investigate the survival data, Kaplan-Meier survival plots and a log rank test were used. In addition, the association between PSMB4 mRNA expression and relapse-free survival (RFS) was evaluated with the online database Kaplan-Meier Plotter (www.kmplot.com). Briefly, '202244_at' (PSMB4 probe number) was entered into the breast cancer-specific area of the database to obtain the Kaplan-Meier survival curves. Hazard ratios (HR) with $95 \%$ confidence intervals (CI) and P-values were displayed on the webpage. In addition, the multivariate analysis was performed with the Cox's proportional hazards model. Statistical significance was set at $\mathrm{P}<0.05$. All statistical analyses were performed using SPSS 17.0 (SPSS, Inc., Chicago, IL, USA) and SigmaPlot 12 statistical (Systat Software, Inc., San Jose, CA, USA) software programs. The data are presented as mean \pm standard deviation (SD). All experiments were conducted for at least three replicates.

\section{Results}

PSMB4 expression in human breast cancer. In order to further elaborate the function of PSMB4 in the development of breast cancer, PSMB4 protein expression was detected by western blot analysis. As shown in Fig. 1, PSMB4 was highly expressed in the 8 tumors, compared with that noted in the adjacent normal tissues. Taken together, PSMB4 may function as a cancerogenic factor in breast cancer.

PSMB4 expression and patient survival. The distribution and expression level of PSMB4 and Ki-67 in 92 breast cancer tissue sections were examined using immunohistochemistry. As shown in Fig. 2A, compared with the adjacent normal tissues, 
Table II. Univariate analysis of the overall survival of the breast cancer patients.

\begin{tabular}{lcccc}
\hline \multirow{2}{*}{$\begin{array}{l}\text { Patient } \\
\text { characteristics }\end{array}$} & Total & \multicolumn{2}{c}{ Survival status } & \\
\cline { 3 - 3 } & Deceased & Alive & P-value \\
\hline $\begin{array}{l}\text { Age (years) } \\
\leq 50\end{array}$ & 48 & 17 & 31 & 0.894 \\
$>50$ & 44 & 15 & 29 &
\end{tabular}

Tumor grade

$\begin{array}{lrrrr}\text { I } & 8 & 5 & 3 & 0.036^{\mathrm{b}} \\ \text { II } & 43 & 18 & 25 & \\ \text { III } & 41 & 9 & 32 & \end{array}$

ER status

$\begin{array}{llll}\text { Negative } & 40 & 13 & 27 \\ \text { Positive } & 52 & 19 & 33\end{array}$

PR status

$\begin{array}{llcc}\text { Negative } & 69 & 27 & 42 \\ \text { Positive } & 23 & 5 & 18\end{array}$

Her2 status

$\begin{array}{lrrr}\text { Negative } & 68 & 25 & 43 \\ \text { Positive } & 24 & 7 & 17\end{array}$

Tumor size $(\mathrm{cm})$

$\begin{array}{lllll}\leq 2.5 & 34 & 17 & 17 & 0.019^{\mathrm{b}} \\ >2.5 & 58 & 15 & 43 & \end{array}$

Lymph node status

\begin{tabular}{lrrrr} 
Negative & 34 & 9 & 25 & 0.200 \\
Positive & 58 & 23 & 35 & \\
Histology & & & & \\
Ductal & 16 & 5 & 11 & 0.744 \\
Others & 76 & 27 & 49 & \\
Ki-67 & & & & \\
Low & 44 & 20 & 24 & $0.040^{\mathrm{b}}$ \\
High & 48 & 12 & 36 & \\
PSMB4 & & & & \\
Low & 34 & 7 & 27 & $0.029^{\mathrm{b}}$ \\
High & 58 & 25 & 33 & \\
\hline
\end{tabular}

a Statistical analyses were performed by the Pearson $\chi^{2}$ test; ${ }^{\text {b }}<0.05$ is considered statistically significant. ER, estrogen receptor; PR, progesterone-receptor.

PSMB4 was highly stained mainly in the cytoplasm and nuclei in poorly differentiated specimens. We next investigated the association between PSMB4 protein level and common clinical parameters of the breast cancer cases. As presented in Table I, positive correlations were found between the expression level of PSMB4 and Ki-67 ( $\mathrm{P}=0.040)$, tumor grade $(\mathrm{P}=0.005)$, and tumor size $(\mathrm{P}=0.047)$. This was compared with the clinicopathological features listed in Table II. Furthermore, the univariate survival analysis revealed that tumor grade $(\mathrm{P}=0.036)$, tumor size $(\mathrm{P}=0.019)$, $\mathrm{PSMB} 4$ expression $(\mathrm{P}=0.029)$, and $\mathrm{Ki}-67$ expression $(\mathrm{P}=0.040)$ were prognostic factors for overall
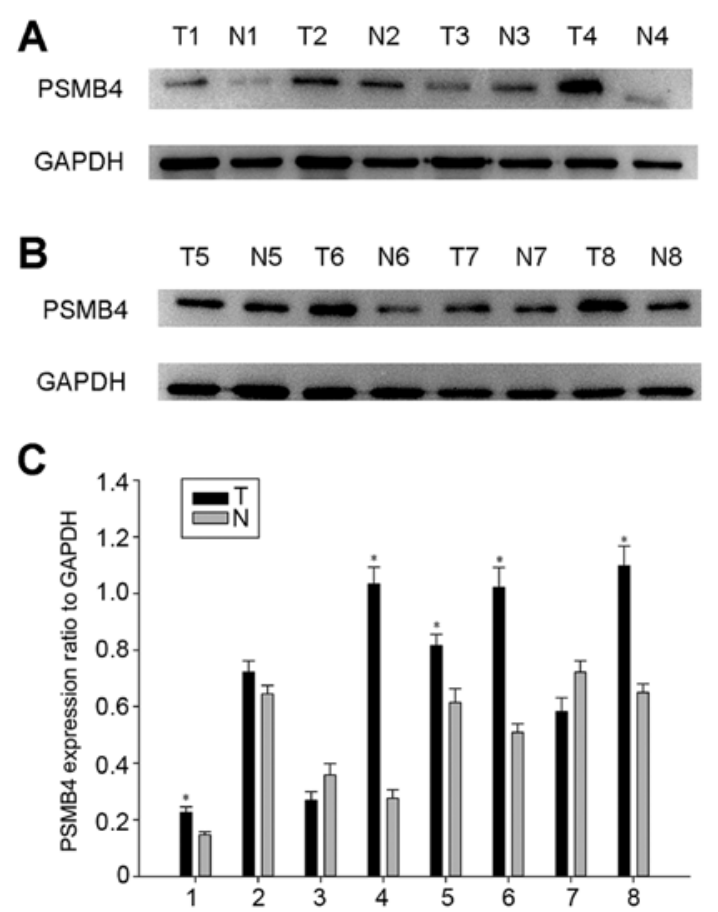

Figure 1. Expression of PSMB4 in human breast cancer. Relative PSMB4 expression levels in breast cancer and adjacent normal tissues. (A and B) Expression of PSMB4 in 8 matched pairs of breast carcinoma tissues (T1-T8) and adjacent normal tissues (N1-N8) was detected by western blot analysis. (C) Quantification of the relative densitometry of PSMB4 expression levels of the matched cancer and adjacent tissues relative to GAPDH. "P $<0.05$.

Table III. Multivariate analysis of overall survival.

\begin{tabular}{lccc}
\hline Variables & HR & $95.0 \%$ CI & P-value \\
\hline Age & 0.600 & $0.275-1.310$ & 0.200 \\
Tumor grade & 0.318 & $0.158-0.640$ & $0.001^{\text {a }}$ \\
ER & 1.426 & $0.628-3.239$ & 0.397 \\
PR & 0.472 & $0.170-1.308$ & 0.149 \\
Her2 & 0.480 & $0.202-1.139$ & 0.096 \\
Tumor size & 0.310 & $0.136-0.704$ & $0.005^{\mathrm{a}}$ \\
Axillary lymph node & 1.855 & $0.760-4.528$ & 0.175 \\
Histology & 1.154 & $0.410-3.247$ & 0.787 \\
Ki-67 & 0.330 & $0.145-0.749$ & $0.008^{\mathrm{a}}$ \\
PSMB4 & 9.670 & $3.291-28.410$ & $0.001^{\mathrm{a}}$
\end{tabular}

HR, hazard ratio; CI, confidence interval, ER estrogen receptor; $\mathrm{PR}$, progesterone receptor. ${ }^{\mathrm{a}} \mathrm{P}<0.05$.

survival (Table II). The multivariate analysis using Cox's proportional hazards model revealed that grade $(\mathrm{P}=0.010)$, tumor size $(\mathrm{P}=0.005)$, $\mathrm{PSMB} 4$ expression $(\mathrm{P}=0.001)$, and $\mathrm{Ki}-67$ expression $(\mathrm{P}=0.008)$ were prognostic indicators for overall survival (Table III). The present results revealed that there was a positive correlation between PSMB4 and Ki-67 (Pearson's correlation coefficient: $\mathrm{r}=0.47, \mathrm{P}<0.01$ ) (Fig. 2B). Subsequently, the relationship between PSMB4 protein level and the survival condition of the 92 patients were examined. As shown in the Kaplan-Meier survival curves, patients with 
A
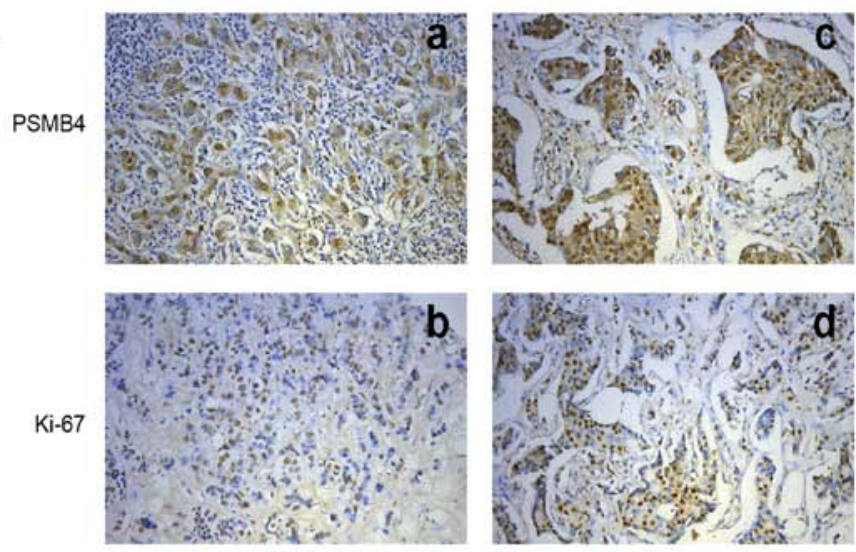
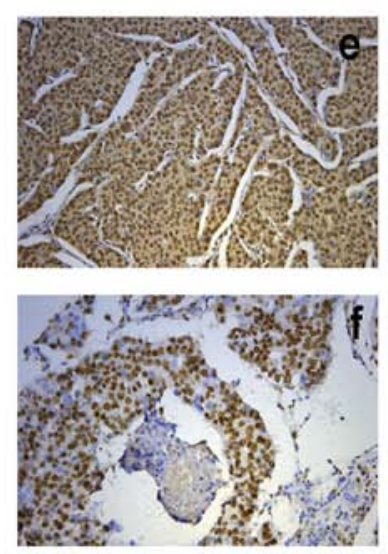

B
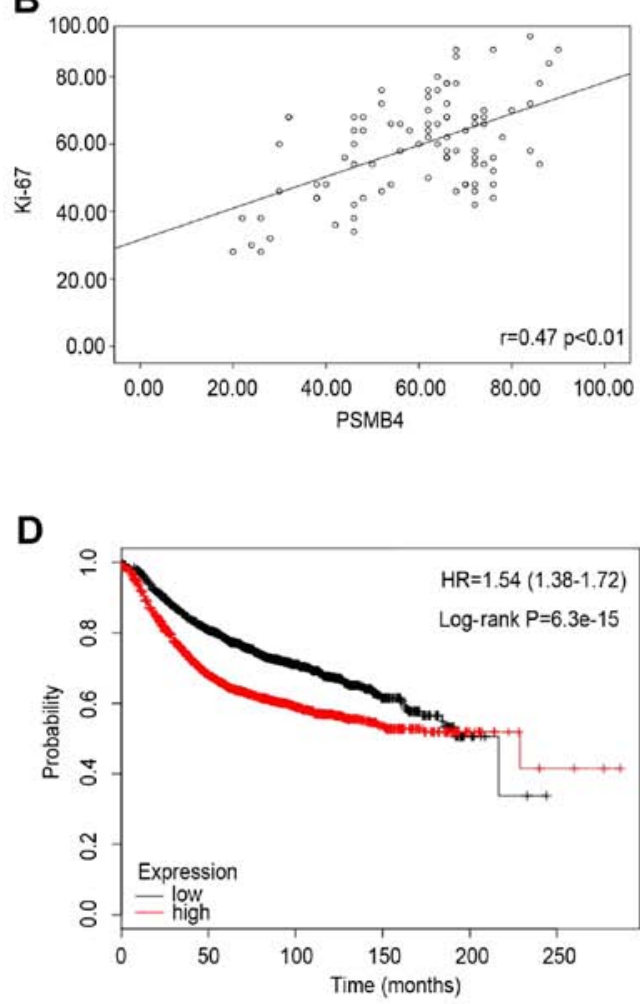

\section{D}

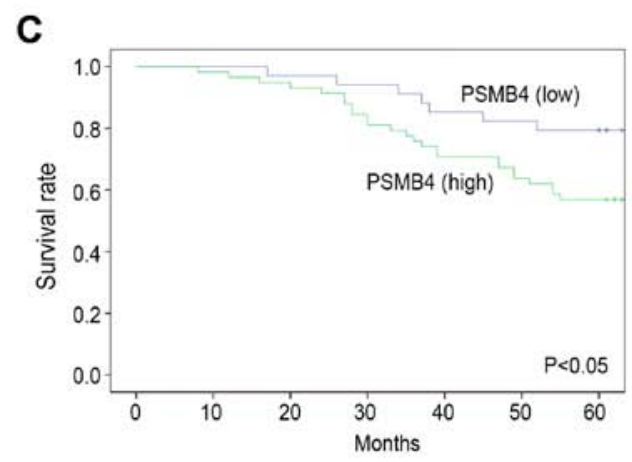

C 
A

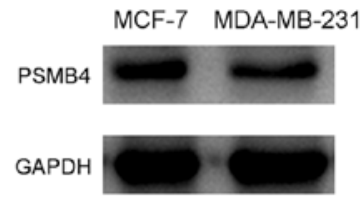

C

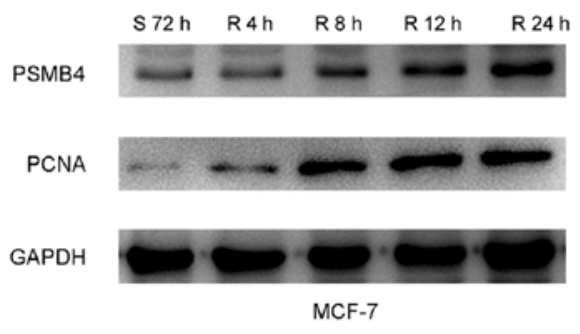

E

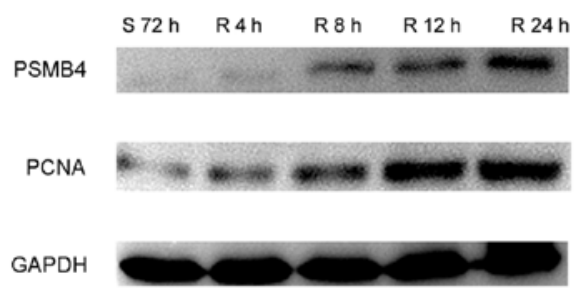

MDA-MB-231

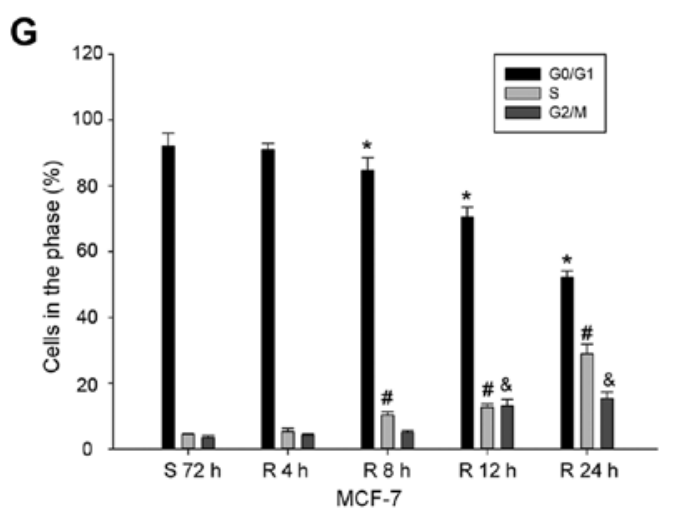

B

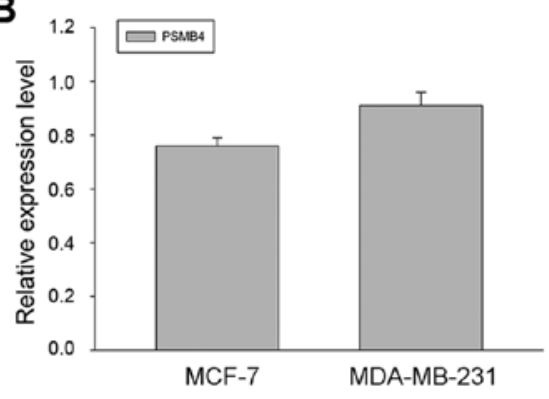

D
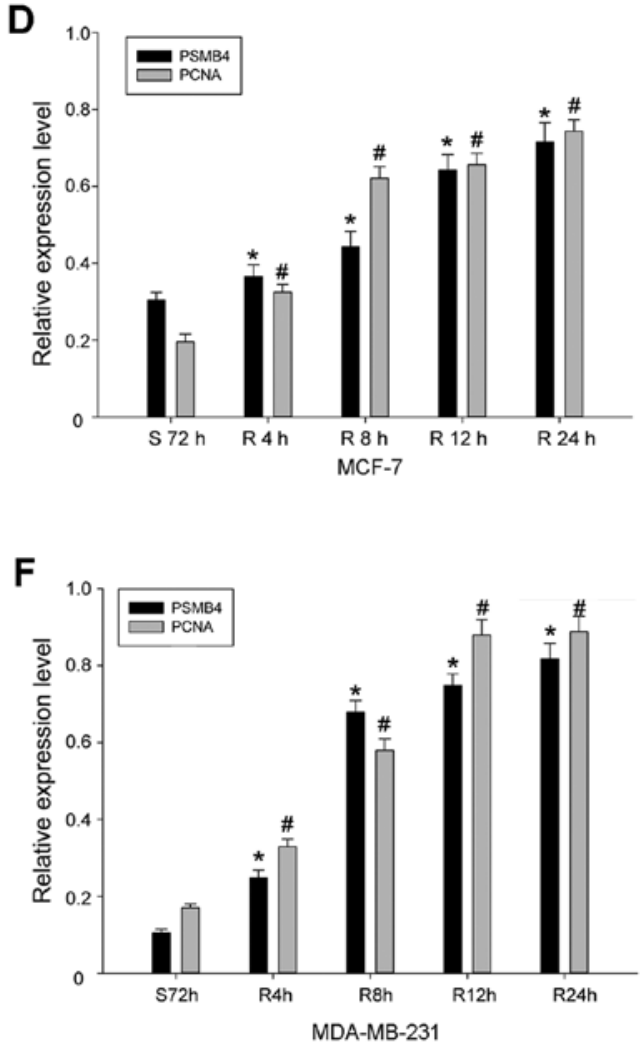

H

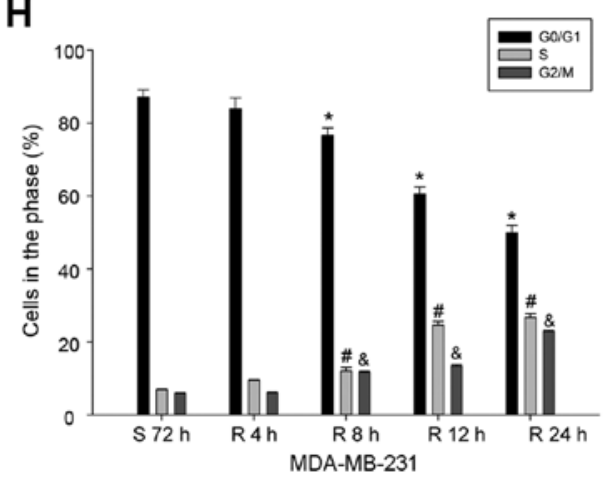

Figure 3. Expression of PSMB4 in different phases of the cell cycle. Expression of PSMB4 in proliferating breast cancer cells is shown. (A) Expression of PSMB4 in two breast cancer cell lines (MCF-7 and MDA-MB-231) was analyzed by western blot analysis. (B) Quantification of the relative densitometry of PSMB4 expression levels relative to GAPDH. (C-F) Expression of PSMB4 and cell cycle-related molecule PCNA in proliferating MCF-7 and MDA-MB-231 cells after serum stimulation. Data were analyzed by Student's t-test; ${ }^{*}, \mathrm{P}<0.05$, compared with control cells serum-starved for $72 \mathrm{~h}$. (G and $\mathrm{H}$ ) Breast cancer cell lines were synchronized at the G1 phase and progressed into the S phase after adding serum at $0,4,8,12$ or $24 \mathrm{~h}$, compared to cells which were serum-starved for $72 \mathrm{~h}(\mathrm{~S} 72 \mathrm{~h}) ;{ }^{*}, \ldots, \& \mathrm{P}<0.05$, compared with control cells serum-starved for $72 \mathrm{~h}$.

detected in the process of serum starvation and refeeding. Most MDA-MB-231 and MCF-7 cells were arrested in the G1 phase after the process of serum deprivation for $72 \mathrm{~h}$. Remarkably, within $24 \mathrm{~h}$ after the release of serum, the number of cells 
A
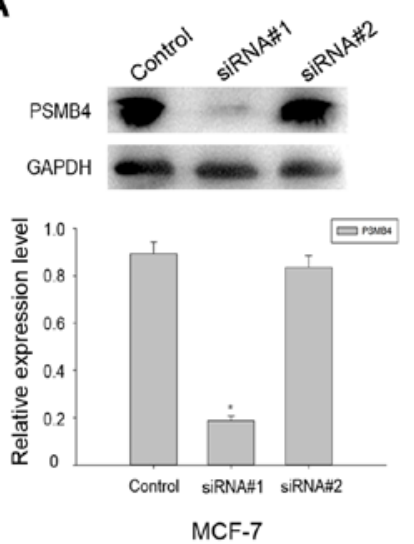

D

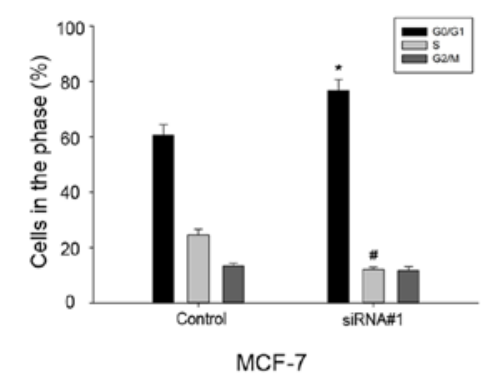

B
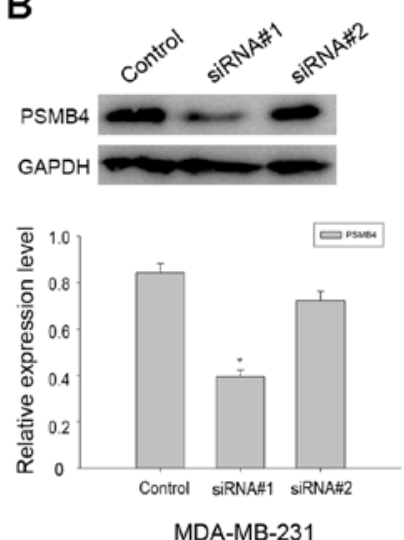

E

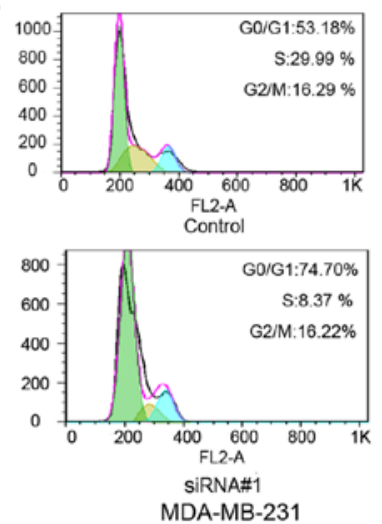

C
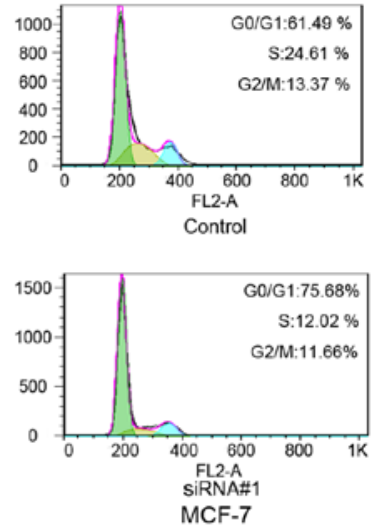

F

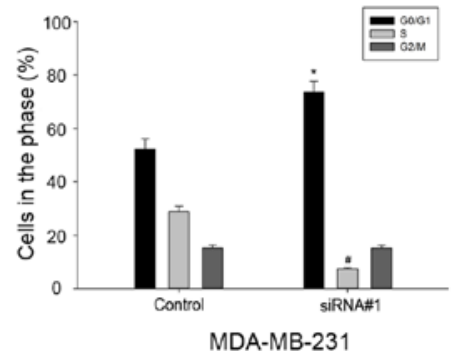

I

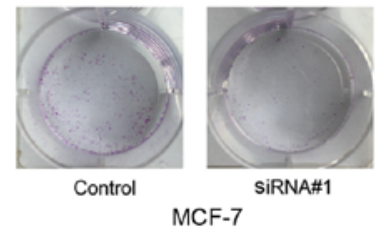

J

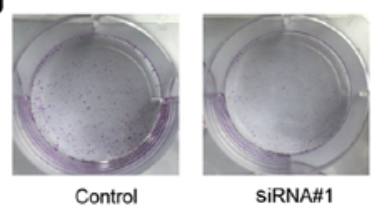

MDA-MB-231

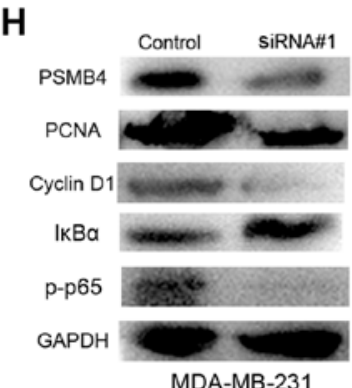

MDA-MB-231

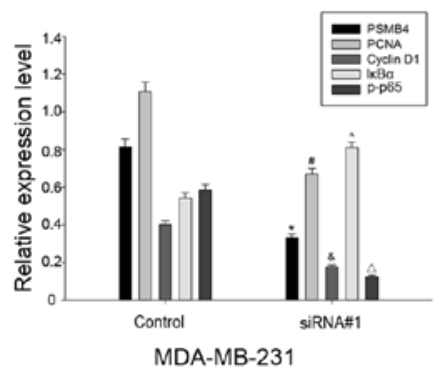

Figure 4. PSMB4 knockdown promotes cell cycle arrest and inhibits cell proliferation through the NF-kB pathway. PSMB4 knockdown inhibited cell proliferation. (A and B) Expression of PSMB4 was significantly decreased $48 \mathrm{~h}$ after knockdown of PSMB4 in the MCF-7 and MDA-MB-231 cells. The bar chart shows the ratio of PSMB4 to GAPDH as measured by densitometry; ${ }^{\mathrm{P}}<0.05$. (C-F) Flow cytometry indicated that PSMB4 knockdown reduced the proportion of cells in the S phase. (G and H) Protein expression of PCNA, cyclin D1, Iк $\beta \alpha$ and p-p65 in MCF-7 and MDA-MB-231 cells following knockdown of PSMB4; $*, \#, \&, \wedge, \perp \mathrm{P}<0.05$, compared with the controls. (I and J) Colony formation analysis.

blocked in the G1 phase gradually decreased from $~ 90$ to $50 \%$, while the expression of PSMB4 gradually increased, which was similar to PCNA (Fig. 3G and H).
PSMB4 knockdown promotes cell cycle arrest and inhibits cell proliferation through the $N F-\kappa B$ pathway. MDA-MB-231 and MCF-7 cells were transfected with PSMB4 siRNA\#1 and 
A
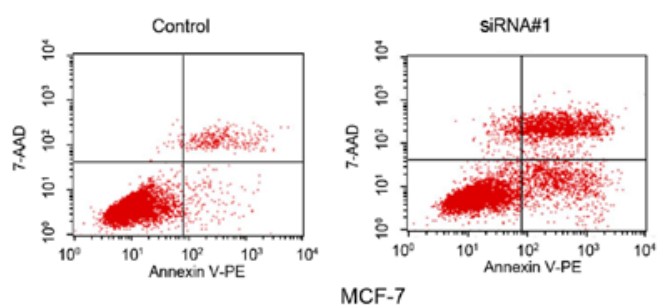

B

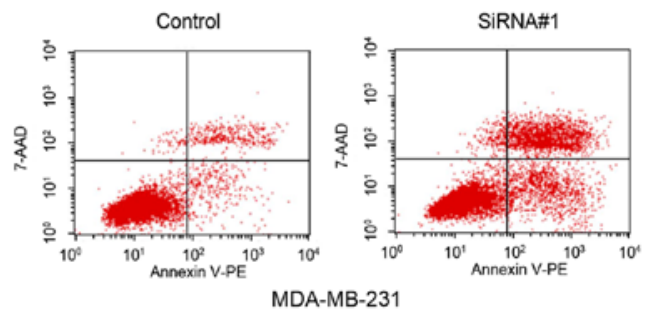

C

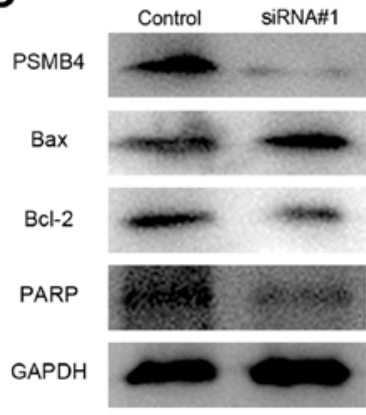

MCF-7

D

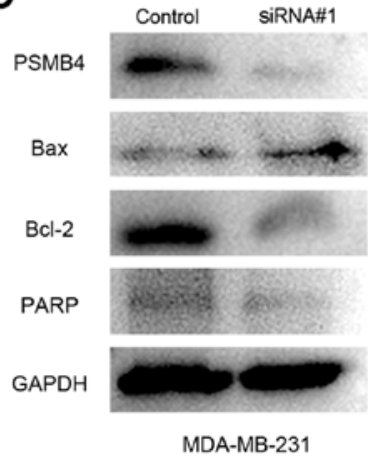

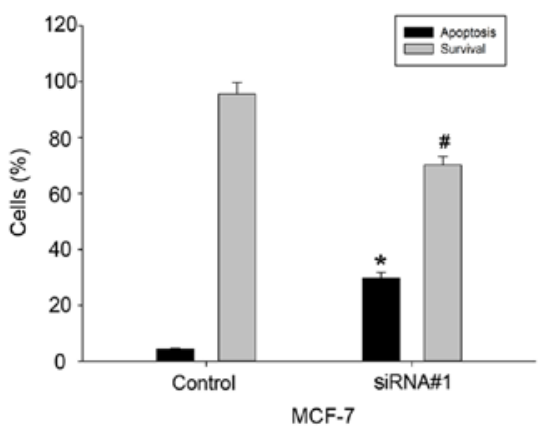
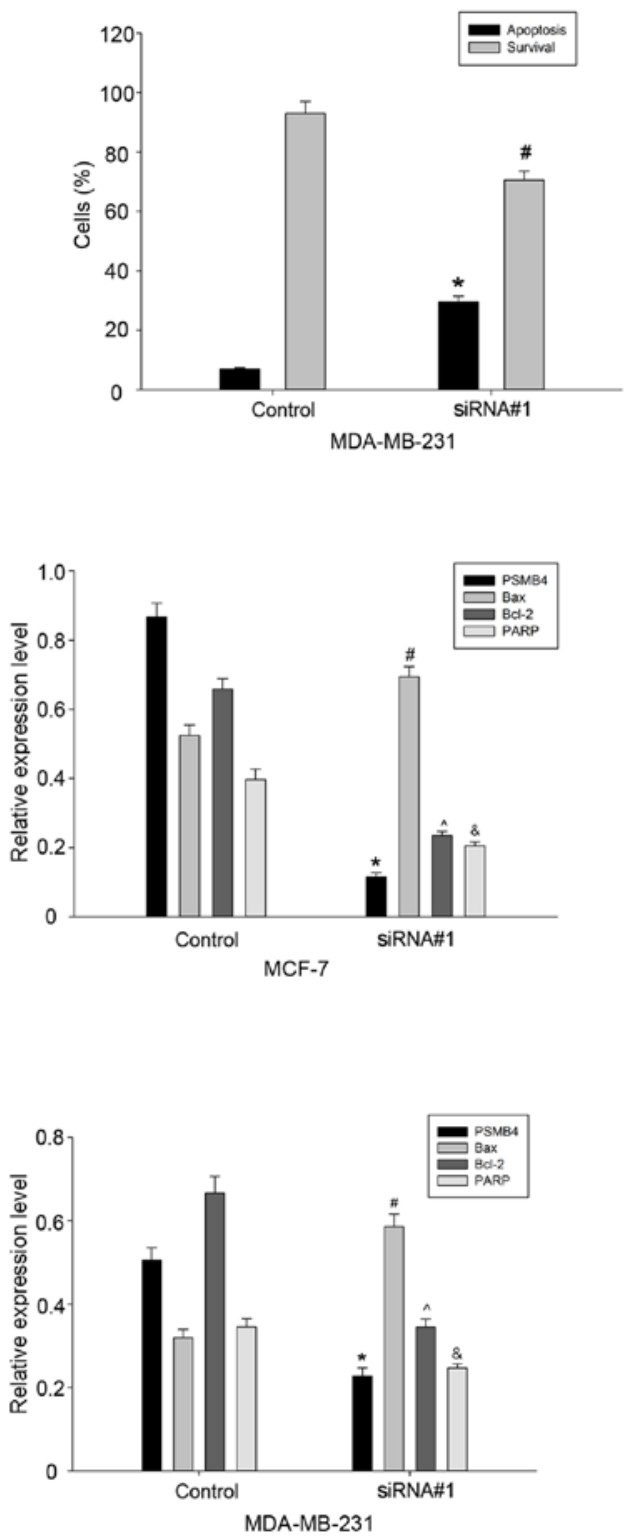

Figure 5. PSMB4 silencing results in the suppression of cell viability. PSMB4 knockdown suppresses cell viability. (A and B) Flow cytometry revealed an increase in cell apoptosis in the MCF-7 and MDA-MB-231 cells transfected with PSMB4-siRNA\#1. (C and D) Protein expression of Bax, Bcl-2 and PARP in MCF-7 and MDA-MB-231 cells following knockdown of PSMB4. These results are presented as the mean \pm standard deviation (SD) of three independent experiments; ${ }^{*, \#, \wedge \&} \mathrm{P}<0.05$, compared with the controls.

control, and the expression of PSMB4 was detected in the transfected cells by western blot analysis. Consequently, we determined the effect of PSMB4 knockdown on cell proliferation (Fig. 4A and B). After the transfection of these cells, it was found that the percentage of cells in the G1 phase was significantly higher than that in the control group (Fig. 4C-F). PSMB4 has been previously reported to modulate the proliferation of ovarian cancer and multiple myeloma cells via the NF- $\kappa B$ pathway. Therefore, we investigated whether the NF- $\kappa B$ pathway is involved in the process of tumor proliferation 
mediated by PSMB4. Then, a number of molecules related to the cell cycle was detected, and it was found that the expression of PCNA, cyclin D1 and p-p65 were significantly reduced, compared with the control group, while I $\kappa \beta \alpha$ was increased (Fig. 4G and $\mathrm{H}$ ). The colony formation analysis also validated our conjecture (Fig. 4I and J). Taken together, it was found that PSMB4 can promote the proliferation of breast cancer cells through the NF- $\mathrm{B}$ pathway.

PSMB4 silencing results in the suppression of cell viability. It has been reported that as a survival gene, PSMB4 knockdown can cause a marked decrease in glioma cell viability. It was hypothesized that PSMB4 could also maintain the viability of breast cancer MDA-MB-231 and MCF-7 cells Therefore, the apoptosis of breast cancer cells transfected with PSMB4-siRNA\#1 or controls was analyzed by flow cytometry (Fig. 5A and B). The results revealed that compared with the control group, the percentage of apoptotic cells was higher in the PSMB4-siRNA\#1 group. Next, a series of molecular markers for cellular apoptosis were analyzed, and it was found that the expression levels of Bcl-2 and PARP were significantly decreased, while the level of the apoptotic marker Bax was increased in the cells transfected with PSMB4siRNA\#1 (Fig. 5C and D). Thus, it is clear that as a survival gene, PSMB4 can maintain the viability of breast cancer cells.

\section{Discussion}

Breast cancer is the second leading cause of cancer-related mortality worldwide. Notwithstanding the utilization of comprehensive diagnostic and therapeutic approaches, the recurrence and metastasis of breast cancer are commonly observed $(19,20)$. Although factors including ER, PR and HER-2 are clinical predictive markers for breast cancer, patients with diverse molecular subtypes have distinct efficacies. Therefore, they cannot fully reflect the molecular mechanisms of breast cancer therapy $(21,22)$. Hence, it is important to identify a molecule that can reveal the mechanism of breast cancer progression.

The proteasome is a family of the multi-catalytic proteinase complex (3), which is crucial to the degradation of preternatural proteins, and involves almost all cellular processes $(4,5)$. Increasing studies have found that the proteasome plays a key role in regulating cell proliferation and migration signaling pathways in various malignant tumors. In the future, proteasome inhibitors are expected to be effective drug targets for the treatment of breast cancer. PSMB 4 , a $\beta 4$ subunit of the $20 \mathrm{~S}$ proteasome, is a member of the ubiquitin-proteasome family, and is involved in the cytoplasmic protein catabolic process $(12,13)$. More and more studies elaborate the correlation between PSMB4 expression and tumor tissues, including ovarian cancer and hepatocellular carcinoma. PSMB4 silencing was found to suppress the viability of cell lines, including glioma and non-glioma cell lines (MCF7 and A549). PSMB4 siRNA led to decreased protein levels of other members of the proteasome subunit (PSMB1, PSMB2 and PSMB5) (15). Furthermore, it has been reported that the subunit of proteasomes stabilizes other subunits during assembly, and decreases the protein level of other members due to the destabilization of the $\beta$-ring assembly pathway, leading to decreased viability (23). Moreover, the cytotoxic effect of proteasome inhibitors on various cell types has been reported, and the PARP decrease was obvious in glioma cells transfected with PSMB4 siRNA (24-26). Therefore, it was demonstrated that PSMB4 knockdown also caused a decrease in PARP. During tumor development, proliferation is an important process that involves many classic pathways, such as the JAK-STAT, $\mathrm{NF}-\kappa \mathrm{B}, \mathrm{PI} 3 \mathrm{~K}$ and mTOR signaling pathways (27-29). As a transcriptional factor $(30,31), \mathrm{NF}-\kappa \mathrm{B}$ can regulate cell proliferation and cell death. Generally speaking, the inhibitor of $\mathrm{NF}-\kappa \mathrm{B}$ can be regulated by the proteasome, and proteasome inhibition can induce depressed $\mathrm{NF}-\kappa \mathrm{B}$ activation and increase cell viability $(32-36)$. Previous studies $(13,14)$ have suggested that PSMB4 can promote the proliferation of ovarian cancer and multiple myeloma through the $N F-\kappa B$ signaling pathway. The present study found that PSMB4 knockdown inhibited the activation of the NF- $\kappa \mathrm{B}$ signaling pathway in breast cancer. Consistent with our hypothesis, it was also verified that there is a PSMB4/NF- $\kappa \mathrm{B}$ signaling pathway in breast cancer. Indeed, these results suggest that PSMB4 can promote proliferation and inhibit apoptosis through the NF- $\kappa \mathrm{B}$ pathway, thereby enhancing breast cancer patient survival.

In summary, it was found that PSMB4 is overexpressed in breast cancer, and its interference can inhibit the proliferation and viability of breast cancer cells. Therefore, it is expected to be an effective target for the treatment of breast cancer.

\section{Acknowledgements}

Not applicable.

\section{Funding}

The present study was supported in part by a grant from the Jiangsu Province Maternal and Child Health Research Project (no. F201682).

\section{Availability of data and materials}

The datasets used during the present study are available from the corresponding author upon reasonable request.

\section{Authors' contributions}

HW and ZH conceived and designed the study. LX, WZ, LX and XY performed the experiments. LX and WZ wrote the manuscript. LX, YX and XR reviewed and edited the manuscript. All authors read and approved the manuscript and agree to be accountable for all aspects of the research in ensuring that the accuracy or integrity of any part of the work are appropriately investigated and resolved.

\section{Ethics approval and consent to participate}

The present study was approved by the Ethics Committee of the Affiliated Cancer Hospital of Nantong University (Nantong, China). All patients provided written informed consent.

\section{Patient consent for publication}

Not applicable. 


\section{Competing interests}

The authors declare that they have no competing interests.

\section{References}

1. Parkin DM, Bray F, Ferlay J and Pisani P: Global cancer statistics, 2002. CA Cancer J Clin 55: 74-108, 2005.

2. Secginli S: Mammography self-efficacy scale and breast cancer fear scale: Psychometric testing of the Turkish versions. Cancer Nurs 35: 365-373, 2012.

3. Peters JM, Franke WW and Kleinschmidt JA: Distinct $19 \mathrm{~S}$ and $20 \mathrm{~S}$ subcomplexes of the $26 \mathrm{~S}$ proteasome and their distribution in the nucleus and the cytoplasm. J Biol Chem 269: 7709-7718, 1994.

4. Tsakiri EN and Trougakos IP: The amazing ubiquitin-proteasome system: Structural components and implication in aging. Int Rev Cell Mol Biol 314: 171-237, 2015.

5. Ling Q and Jarvis P: Functions of plastid protein import and the ubiquitin-proteasome system in plastid development. Biochim Biophys Acta 1847: 939-948, 2015.

6. Csizmar CM, Kim DH and Sachs Z: The role of the proteasome in AML. Blood Cancer J 6: e503, 2016

7. Lee GY, Haverty PM, Li L, Kljavin NM, Bourgon R, Lee J, Stern H, Modrusan Z, Seshagiri S, Zhang Z, et al: Comparative oncogenomics identifies PSMB4 and SHMT2 as potential cancer driver genes. Cancer Res 74: 3114-3126, 2014.

8. Zhong J, Shaik S, Wan L, Tron AE, Wang Z, Sun L, Inuzuka H and Wei W: SCF $\beta$-TRCP targets MTSS1 for ubiquitinationmediated destruction to regulate cancer cell proliferation and migration. Oncotarget 4: 2339-2353, 2013.

9. Kim YH, Kim JH, Choi YW, Lim SK, Yim H, Kang SY, Chung YS, Lee GY and Park TJ: Gankyrin is frequently overexpressed in breast cancer and is associated with ErbB2 expression. Exp Mol Pathol 94: 360-365, 2013.

10. Manasanch EE and Orlowski RZ: Proteasome inhibitors in cancer therapy. Nat Rev Clin Oncol 14: 417-433, 2017.

11. Pellom ST Jr and Shanker A: Development of proteasome inhibitors as therapeutic drugs. J Clin Cell Immunol S5: 5, 2012.

12. Nandi D, Woodward E, Ginsburg DB and Monaco JJ: Intermediates in the formation of mouse 20S proteasomes: Implications for the assembly of precursor beta subunits. EMBO J 16: 5363-5375, 1997

13. Liu R, Lu S, Deng Y, Yang S, He S, Cai J, Qiang F, Chen C, Zhang W, Zhao S, et al: PSMB4 expression associates with epithelial ovarian cancer growth and poor prognosis. Arch Gynecol Obstet 293: 1297-1307, 2016.

14. Zhang Y, Liu H, Cui M, Liu J, Yi R, Niu Y, Chen T and Zhao Y: Effect of the HBV whole-X gene on the expression of hepatocellular carcinoma associated proteins. J Microbiol Immunol Infect 49: 335-343, 2016.

15. Valdagni R, Rancati T, Ghilotti M, Cozzarini C, Vavassori V, Fellin G, Fiorino C, Girelli G, Barra S, Zaffaroni N, et al: To bleed or not to bleed. A prediction based on individual gene profiling combined with dose-volume histogram shapes in prostate cancer patients undergoing three-dimensional conformal radiation therapy. Int J Radiat Oncol Biol Phys 74: 1431-1440, 2009.

16. Zheng-Hao D, Ji-Fang W, De-Sheng X and Jian-Hua Z: Galectin-1 is up-regulated by RASSF1A gene in human gastric carcinoma cell line SGC7901. APMIS 120: 582-590, 2012.

17. Thaker NG, Zhang F, McDonald PR, Shun TY, Lewen MD, Pollack IF and Lazo JS: Identification of survival genes in human glioblastoma cells by small interfering RNA screening. Mol Pharmacol 76: 1246-1255, 2009.

18. Zheng P, Guo H, Li G, Han S, Luo F and Liu Y: PSMB4 promotes multiple myeloma cell growth by activating NF- $\mathrm{BB}-\mathrm{miR}-21$ signaling. Biochem Biophys Res Commun 458: 328-333, 2015.

19. Runowicz CD, Leach CR, Henry NL, Henry KS, Mackey HT, Cowens-Alvarado RL, Cannady RS, Pratt-Chapman ML, Edge SB, Jacobs LA, et al: American Cancer Society/American Society of Clinical Oncology Breast Cancer Survivorship Care Guideline. J Clin Oncol 34: 611-635, 2016.
20. Adamczyk A, Niemiec JA, Ambicka A, Mucha-Małecka A, Mituś J and Ryś J: CD44/CD24 as potential prognostic markers in node-positive invasive ductal breast cancer patients treated with adjuvant chemotherapy. J Mol Histol 45: 35-45, 2014

21. Chen XS, Wu JY, Huang O, Chen CM, Wu J, Lu JS, Shao ZM, Shen ZZ and Shen KW: Molecular subtype can predict the response and outcome of Chinese locally advanced breast cancer patients treated with preoperative therapy. Oncol Rep 23: 1213-1220, 2010

22. Yao N, Song Z, Wang X, Yang S and Song H: Prognostic Impact of Progesterone Receptor Status in Chinese Estrogen Receptor Positive Invasive Breast Cancer Patients. J Breast Cancer 20: 160-169, 2017.

23. Hirano Y, Kaneko T, Okamoto K, Bai M, Yashiroda H, Furuyama K, Kato K, Tanaka K and Murata S: Dissecting beta-ring assembly pathway of the mammalian 20S proteasome. EMBO J 27: 2204-2213, 2008.

24. Poulaki V, Mitsiades CS, Kotoula V, Negri J, McMillin D, Miller JW and Mitsiades N: The proteasome inhibitor bortezomib induces apoptosis in human retinoblastoma cell lines in vitro. Invest Ophthalmol Vis Sci 48: 4706-4719, 2007.

25. Yin D, Zhou H, Kumagai T, Liu G, Ong JM, Black KL and Koeffler HP: Proteasome inhibitor PS-341 causes cell growth arrest and apoptosis in human glioblastoma multiforme (GBM). Oncogene 24: 344-354, 2005.

26. Fribley A, Zeng Q and Wang CY: Proteasome inhibitor PS-341 induces apoptosis through induction of endoplasmic reticulum stress-reactive oxygen species in head and neck squamous cell carcinoma cells. Mol Cell Biol 24: 9695-9704, 2004

27. Zhou B, Damrauer JS, Bailey ST, Hadzic T, Jeong Y, Clark K, Fan C, Murphy L, Lee CY, Troester MA, et al: Erythropoietin promotes breast tumorigenesis through tumor-initiating cell selfrenewal. J Clin Invest 124: 553-563, 2014.

28. Templin J, Atanackovic D, Hasche D, Radhakrishnan SV and Luetkens T: Oscillating expression of interleukin-16 in multiple myeloma is associated with proliferation, clonogenic growth, and PI3K/NFKB/MAPK activation. Oncotarget 8: 49253-49263, 2017.

29. Eroles P, Bosch A, Pérez-Fidalgo JA and Lluch A: Molecular biology in breast cancer: Intrinsic subtypes and signaling pathways. Cancer Treat Rev 38: 698-707, 2012.

30. Abdel-Mageed AB and Agrawal KC: Activation of nuclear factor kappaB: Potential role in metallothionein-mediated mitogenic response. Cancer Res 58: 2335-2338, 1998.

31. Biswas DK, Cruz AP, Gansberger E and Pardee AB: Epidermal grow th factor-induced nuclear factor kappa B activation: A major pathway of cell-cycle progression in estrogen-receptor negative breast cancer cells. Proc Natl Acad Sci USA 97: 8542-8547, 2000.

32. Grundler K, Rotter R, Tilley S, Pircher J, Czermak T, Yakac M, Gaitzsch E, Massberg S, Krötz F, Sohn HY, et al: The proteasome regulates collagen-induced platelet aggregation via nuclearfactor-kappa-B (NFKB) activation. Thromb Res 148: 15-22, 2016.

33. Di Filippo C, Petronella P, Freda F, Scorzelli M, Ferretti M, Canonico S, Rossi F and D'Amico M: Involvement of the ubiquitinproteasome system in the formation of experimental postsurgical peritoneal adhesions. Mediators Inflamm 2012: 194723, 2012.

34. Pajonk F and McBride WH: The proteasome in cancer biology and treatment. Radiat Res 156: 447-459, 2001.

35. Ehrlich ES, Chmura JC, Smith JC, Kalu NN and Hayward GS: KSHV RTA abolishes NFKB responsive gene expression during lytic reactivation by targeting vFLIP for degradation via the proteasome. PLoS One 9: e91359, 2014.

36. Kiliccioglu I, Konac E, Varol N, Gurocak S and Yucel Bilen C: Apoptotic effects of proteasome and histone deacetylase inhibitors in prostate cancer cell lines. Genet Mol Res 13: 3721-3731, 2014. 